\title{
STUDY ON THE CONSTRUCTION AND APPLICATION OF 3D GEOGRAPHIC INFORMATION SERVICES FOR THE SMART CITY
}

\author{
MAO Wei-qing ${ }^{\mathrm{a}}$
}

a Shanghai Surveying and Mapping Institute, Shanghai, China - wqmao731012@qq.com

KEY WORDS: Smart City; Urban 3D Geographic Information; Rapid Modelling; Indoor Modelling

\begin{abstract}
:
Smart City, whose main characteristics are intelligence and interconnection capability, has become an important goal of some cities' development. This paper, based on urban three-dimensional geographic information characteristics, analyses 3D geographic information requirements in the Smart City construction and development process, proposes construction and management methods for 3D geographic information. Furthermore, this paper takes Shanghai Geographic Information Public Service Platform as an example, discusses 3D geographic information application in multiple fields, and proves that it is an effective ways to promote Intelligent City construction.
\end{abstract}

\section{INTRODUCTION}

Smart City can be defined as a combination of digital city and internet of things ${ }^{[1]}$. Smart City, whose major features are intelligence and interoperability, has become an important development goal for large cities. Geographic Information Sharing mechanism and platforms have become an important part of fundamental development in the three-year action plan to build smart city in Shanghai. Today, as the development of information technology, geographic information also shows its importance in many area. In order to support smart city's construction and operation, geographic information public service platform can provide geographic information data, interfaces and web services according to the need of users.

Currently, the connotation of geographic information has been enriched by the development of a large variety of applications, these applications use three-dimensional data rather than traditional two-dimensional vector or image data. Urban 3D GIS, extended from traditional 2D GIS, become mature by providing photorealistic city scene to people. Urban 3D GIS presents reality in virtual environment with real geographic coordinates. More important, it has capabilities to do spatial analysis. When dealing with complex city problem, urban 3D GIS can help people build a comprehensive concept and intuitive feeling. With the development of wireless technology, location based application become popular and can be used indoor and underground. ${ }^{2]}$ We can expect that urban 3D GIS will play an important role during the development of smart city.

Shanghai Surveying and Mapping Institute has been conducting urban 3D GIS research for many years and contributed a lot to the development of urban 3D GIS. Shanghai geographic information public service platform has released 3D GIS services, which have been used successfully in many areas of smart city. These 3D GIS services has the characteristics of high efficiency, great visual effects, wide coverage, up to date data and so on. Furthermore, the impression that 3D GIS is useless is changed by these 3D GIS services. In summary, this article will discuss the features of 3D GIS, according to Shanghai smart city development requirements, and its implementation, management and application.

\section{THE DEMAND ANALYSIS OF URBAN 3D GIS IN SMART CITY}

Smart City extends traditional urban informationization and digital city. It also includes construction of network system and other foundational projects such as geography information public service platform ${ }^{[4]}$. Urban 3D GIS has played a key role during the development of smart city, it has the ability to integrate isolated position information through the power of Internet, form an integrated system with cooperation and selfadjustment capability. This technology could meet the demand of public service personalization, city management refinement, government service facilitation and industry development intellectualization. The demand of urban 3D GIS for Smart City can be summarized as follows:

\subsection{Sharing massive information online}

As the most obvious character of smart city, interconnection is the necessary condition for sharing geographic information online. Urban 3D geospatial information represents a virtualization of a real city including not only regular geospatial information such as DEM, DOM, DLG etc., but also massive model datasets and texture pictures. Higher delicate dataset could reflect a more vivid 3D scene, but it requires high volume data. Take Shanghai as an example, the size of the 3D dataset can be nearly $400 \mathrm{G}$ large only for an area of $700 \mathrm{~km}^{2}$. In order to show the power of 3D geospatial information, the problem of utilizing massive information online needs to be solved first.

\subsection{Put features into different layers}

Layer, as basic storage unit in GIS, is used to represent different types of spatial entities. 3D geospatial information system put different geographic entities into different layers, these geographic entities has the similar properties, characters and topological relations. Compare to 2D GIS, 3D GIS needs more attention on this. There are some similarities between 2D and 3D geospatial information, in classifying the features based on some basic principles, like the classification of buildings, bridges or construction subsidiary facilities into different layers. 
However, 3D geospatial information focuses more on application. For instance, a building can either be displayed as a whole entity or be split into different parts. On one hand, it is essential to display a building as a whole for emergency support service, while on the other hand, subsidiary facilities such as billboard need to be modelled individually for municipal landscape service. In addition, the power of 3D geospatial information lies in vivid virtual reality, which is based on detailed texture information and rendering technology. Implementing 3D geographic information requires high standard data production and management.

\subsection{Accuracy of 3D geospatial data}

3D geospatial information focuses on the position accuracy in both horizontal and vertical dimensions. Landscape analysis requires high vertical accuracy in key areas. 3D geospatial information is able to present the spatial relationship between grounds and undergrounds, this relationship cannot be achieved through traditional 2D geographic data. In digital city, only by integrating the scene of ground and underground, can we archive the goal to make the digital city complete. ${ }^{[5]}$ The underground pipes management system is an important application of 3D underground space, where 3D expression can be used to study cross sections and longitudinal of underground pipelines. It is much easier for administrator to examine the reasonability of the pipeline layout at different stages (e.g. pipeline planning, designing and constructing) using 3D underground exhibition.

\subsection{Dynamic data update of 3D analysis}

The up-to-date spatial data has been a crucial criteria to evaluate the practical value of GIS system. Construction of the realistic 3D urban scene requires new technology. The virtual city presented in 3D geographic information is different from regular city advertising video. Being the foundation of spatial information in smart city, 3D geographic data therefore must be associated with comprehensive geospatial databases, as well as various specialized databases. For example, the real-time query based on some specialized information (e.g., attributes of human and social activities) can provide service information for policy makers.

\section{THE PRACTICE OF IMPLEMENTING MUNICIPAL 3D GEOGRAPHIC INFORMATION}

As the concept of smart city is widely accepted, the 3D GIS is used in many areas. Based on Shanghai geographic information public service platform, Shanghai Surveying and Mapping Institute has successfully implemented 3D GIS in the areas of urban planning, city appearance administration, cultural relic protection, weather forecasting and fire control. The following examples will provide more details.
3.1 First: municipal 3D geographic information can provide emergency services for public security. During the Shanghai EXPO, in order to meet the needs of the Central Security Bureau, State Office of Emergency Management, Garrison Headquarter of Nanjing military region, public security bureau of Shanghai, state security agency of Shanghai, world expo organizing committee and executive committee of Shanghai, the key areas, including the EXPO sites and the Yan An Road Viaduct, were presented in 3D GIS.

3.2 Second: municipal 3D geographic information provides diversified services for planning and management. Using real and accurate $3 \mathrm{D}$ visualization, regulatory elements become three dimensional, change the control and guidance from twodimensional to three dimensional (Fig.1) . Based on this development, Shanghai Surveying and Mapping Institute has created many three-dimensional modelling and pilot applications in the core area of HongQiao business function zone, HengShan Road(for road appearance protection) and ShiLiuPu (an old port). These 3D applications have met the demand of urban planning, design, project review and approval and scenic demonstration. The supplementary licensing system based on 3D application can compare construction plan with regulatory index automatically (Fig.2), and decide whether the construction plan meets the regulatory index.

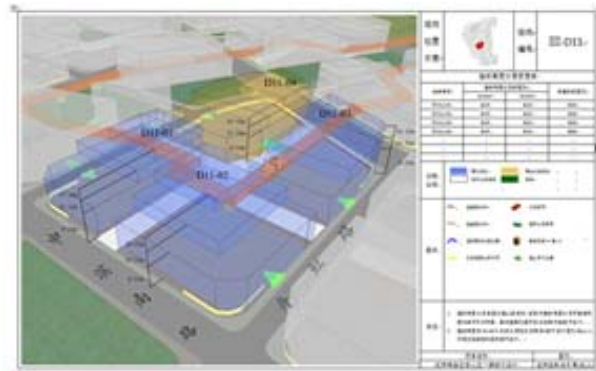

Figure 1. The definition of control and guidance for threedimensional business district space

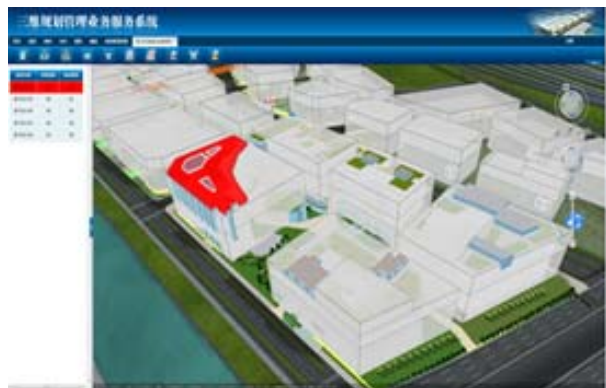

Figure 2. The assisted approval system of three-dimensional construction programs 
3.3 Third: 3D geographic information facilitates outdoor advertisement management. It can show the outdoor advertisement in 3D, make it easy to monitor outdoor advertisement. An advertisement management system can be build based on the 3D geographic information. Overlaying advertisement planning space model with current buildings allows outdoor advertising board administrators monitor outdoor building advertising layout through muti-angle (Fig.3). It can also reflect the difference between outdoor advertising planning layout and current layout intuitively.

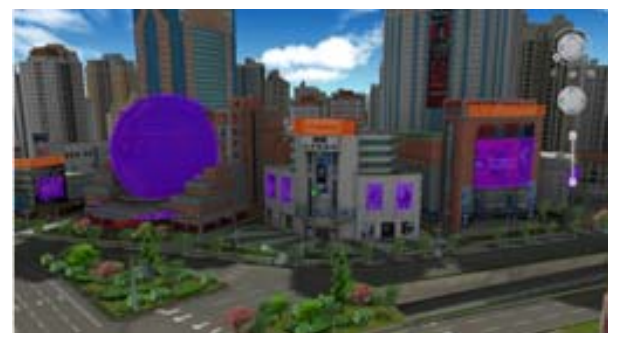

Figure 3. The overlay effect of outdoor advertising in the planning

3.4 Third: municipal 3D geographic information can serve smart fire suppression. Smart fire suppression depends on Internet, virtualization, GIS service and many other technology, including dynamic data collection for professional fire protection, real time monitoring and scheduling of emergency rescuing power, real time checking of Fire pump, water pressure, detection alarm, fire door, smoke control, and real time access of fire site image and rescuing plan. Combined with fire protection application, fire protection resource allocation can be shown in 3D scene of the 3D command system. In the meantime, urban development can be reflected in virtual 3D environment, change the daily excise to muti-dimensions real exercise. During fire suppression, special requirements are needed for organizations like subway station, tunnel construction site, chemical industry zone, industrial park, underground commercial facilities. In order to make the officer learn the building structure in more details, indoor facilities were modelled in 3D. Fire officer can choose to look which floor he want examine. The map will automatically be displayed in split screen in 2D and 3D. This function allows fire safety officer understand the structure of the building, assists officer to deploy right resource to right places (Fig. 4).

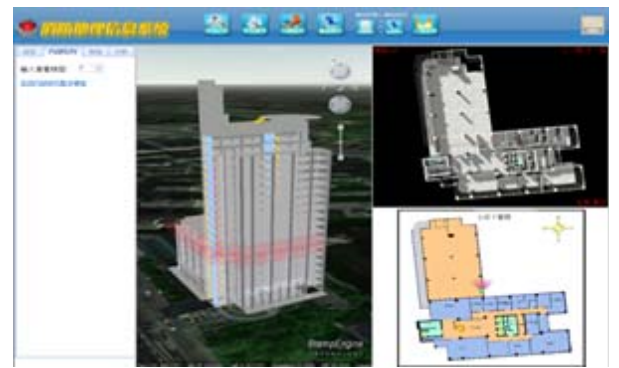

Figure 4. Three-dimensional performance in fire geographic information system
3.5 Fifth, municipal 3D geographic information provides services in diverse aspects for social development. The innovation in 3D technology can help to show all-around topography and building structures. 3D technology has the advantage to display municipal development to investors and tourists, and provide virtual Internet map service to citizens. 3D technology can further be used for dynamic modelling in urban accident and emergency response. Moreover, 3D technology allows user to see underground construction space, supports municipal management and decision making.

\section{CONSTRUCTION AND MANAGEMENT OF MUNICIPAL 3D GEOGRAPHIC INFORMATION}

The continuous implementation of municipal 3D geographic information requires sophisticated data updating mechanism. 3D geographic information is consists of DEM, topography data, model data, video data, and 2D vector data and attribute data. The most complex data is the 3D mode data. In the process of smart city development, 3D model data are used in all spaces. So maintain the product and management process of 3D model data, is the key to 3D geographic information development.

First of all, it's good to adopt spatial database management system. The size of 3D model data is huge. 3D model data is stored in file system traditionally. How to manage these data is quite challenging. Nowadays, people can store 3D spatial entity and relevant texture, attribute data in spatial database. For example, Oracle $10 \mathrm{~g}$ and later versions can use spatial index based on Octree to analyse 3D space quickly. Also, Oracle spatial database can maintain the version information of the $3 \mathrm{D}$ spatial entity record.

The follow important thing is produce 3D data that can be managed by effective system, which consists of 3D model data maintaining, data retrieval, data extraction and quality inspection. A system that could guarantee the data is used efficiently. Currently, the 3D model data of Shanghai has covered major area of the unban city and part of suburban. The city also have large scale production ability. The 3D data production management system also helps the producer to describe data in more detail. Also it can help users to have a comprehensive understanding of data, increase the efficiency of data use, and finally achieve the goal of high quality 3D data creation and update.

The research of automatic 3D data modelling can increase the efficiency of city 3D model data production. ${ }^{[3]}$ The low efficiency of the data production is the main factor that limits the development of 3D geographic information. 3D geographic information technology is a collection of many information technologies. The automatic production process has to rely on these technologies. And a good management procedure is also needed. Currently, oblique photograph and laser radar technology are two main mature methods in 3D model data production. However, due to the complex expression of 3D model data and diversity of implementation, there are still a lot limitations. 3D model componentization technology can build urban underground pipeline and management unit automatically, this can resolve the high cost and long cycle issues.

\section{CONCLUSION:}

With the development of technology, municipal informationization has become an inevitable trend. The development of smart city become the goal of municipal 
informationization development. 3D geographic information technology has become one of the hot technologies that draws a lot attention. Recently, National geographic information bureau of surveying and mapping proposes smart city space and temporal information cloud platform. This platform consider 3D geographic information as one of the most important contents in the platform. This essay use the work in Shanghai as an example, discuss the demand, application, and production management of 3D geographic information. Compared to 2D geographic information, 3D geographic information is not mature yet. There are no common standard and rules. Many areas need to be explored in the future.

\section{Appendices:}

[1] LI Deren. Theory and Practice from Digital City to Smart City [J] • GEOSPATIAL INFORMATION, 2011（6） 15.

[2] ZHU Qing, LI Deren1. The Design and Implementation of Cyber City GIS [J]. Geometrics and Information Science of Wuhan University, 2001, 26(3):8

[3] WANG Min-qi; Research on Construction and Application of Three Dimensional

Urban Geographic Information System [J]. Journal of Gansu Lianhe University (Natural Sciences), 2009 (11)46—49

[4] Jiao Xi, Zhu Wenying, Huang Ruifeng; An Analysis of the Importance of Fundamental Geographical Data in Smart City Construction [J]. Land and Resources Informatization, 2012 (2) $55-61$

About the author: WEIQING MAO, Shanghai Surveying and Mapping Institute ,Senior Engineer, No 419 WuNing Road Shanghai 200063,Mobile: 13764537620, Email:wqmao731012@qq.com. 